\title{
Low-speed wind tunnel testing control systems research
}

\author{
Jinbo Yao Qingyu Yang Yueming Yang Xiujuan Liu \\ Air Force Aviation University \\ Changchun,china \\ ccyym1@126.com
}

\begin{abstract}
The wind tunnel test control is the key to the wind tunnel tests. This article Studied $0.75 \mathrm{~m} \times 0.75 \mathrm{~m}$ With backflow wind tunnel measurement and control technology, through the transformation of the wind tunnel motor to improve the stability and uniformity of the airflow and reduce turbulence degree; through transform angle institutions, increase the angle of attack, sideslip angle and roll angle finesse; through the study of data acquisition and control system, to ensure the fidelity of the data. Effectively improve the scientific nature of the wind tunnel.
\end{abstract}

Keywords-wind tunnel;wind tunnel test and measurement ; control bus structure

\section{OUTLINE}

The wind tunnel i`s one of the basic means of aerodynamic research, simulation test device is used to generate the synthetic wind and artificial airflow through the wind tunnel test model of the (amount) of each point on the air pressure, and other characteristics can be tested to obtain the wind total load distribution of the data, and used to study the model of the aircraft and other objects in effect when the air movement or airflow aerodynamic. Currently widely used in the aerospace, weapons, industrial, agricultural, construction, energy, shipbuilding.

\section{THE WIND TUNNEL INDICATORS REQUIREMENTS AND TEST PARAMETERS MEASURED}

Generated airflow device is the heart of the wind tunnel, the wind tunnel test system is the eyes and ears of the wind tunnel data accuracy and precision is to ensure that the trial is successful very important part of the wind tunnel test of the performance of the test system it is very important.

\section{A. Some of the indicators of the wind tunnel device requirements}

For the wind tunnel, the stability of the air flow is critical to the data related to the measurement, whether it is true, can be applied to the actual items commonly used indicators are as follows: (1) flow stability (relative fluctuation amount of not more than $\sigma \leqslant \pm 0.25 \%$; uniform (2) speed (sectional various points airflow velocity and the cross-sectional flow average velocity rms deviation); (3) direction of uniformity (the airflow direction and wind tunnel axis angle $\ngtr \pm 0.5^{\circ}$ $\pm 0.75^{\circ}$; (4) turbulence intensity (low-speed wind tunnel, the original airflow turbulence intensity $\varepsilon \leqslant 0.16 \%$.

\section{$B$. The parameters of the wind tunnel measurements}

Conventional force measurement, load test, the flow field
Proofread measured, dynamic test in the wind tunnel tests.

Measurement parameters in a routine test in the balance signal, lift, drag, side force, yawing moment, pitching moment, and manipulate a variety of surface hinge moment. Balance chamber pressure balance chamber temperature, the model at the bottom of the pressure, wind tunnel total pressure, static pressure, total temperature, angle of attack: there are about a dozen to two dozen parameters.

Pressure measurement of the surface of the model parameters are dozens of points to a few dry spots. Dozens of points to hundreds of wind tunnel scale pressure measurement parameters. Dynamic test parameters fluctuating pressure and various alternating vibration signal. General points to dozens of points.

$C$ Wind tunnel measurement principles

Wind tunnel experiment data quality level is assessed by the size of the magnitude of the experimental data uncertainty, data uncertainty assessment is the key to the entire wind tunnel experiment we design a test study process, given the wind tunnel experiment research process and factors affecting the uncertainty of the experimental data, do the following: (1) the purpose of wind tunnel experiments and uncertainty analysis of the experimental data presented at the same time, while conducting experimental design, the experimental data uncertainty estimates; (2 ) the uncertainty of the experimental data analysis throughout the whole process of experiment; (3) the quality of the experimental data for the wind tunnel experiment with a "veto"; (4) the uncertainty analysis of the experimental data and estimates is an important component of the experiment reported part; (5) the experimental design and test the system reliability is to ensure that the key aspects of the quality of experimental data; (6) does not consider the air compressibility; (7) to consider an air compression.

\section{WIND TUNNEL TEST SYSTEM DESIGN}

\section{A. The basic requirements of the wind tunnel test system}

The wind tunnel test system should meet the following requirements: (1) online self-calibration function. Can be detected in the process of conducting wind tunnel tests, diagnostics and troubleshooting, improve test efficiency and ensure the reliability of test data. (2) satisfy the unified platform under a detection completion of the wind tunnel test, the routine tests, special tests and dynamic tests. (3) multi-trigger mode in order to meet the requirements of the test. (4) should have an intuitive display detection process and means, and has a friendly interface. (5) has the stability 
to ensure the accuracy of the test data in a complex work environment.

\section{B. Test Systems Analysis}

Testing equipment for wind tunnel tests continue development toward the high-precision, intelligent, high reliability direction module instrument computer most of the wind tunnel test, its intelligent measurement principle is to be completed by some external modular instrument and data back to the computer, display, printing, computing function. Modular instrument bus structure integrated A / D converter, interrupt system, high integration, small size, strong function, low-power, anti-interference ability, stable and reliable, flexible assembly, affordable advantages.

Bus structure, mining is a mature technology, reliability, modular instruments have a high degree of integration, as laboratory equipment can be a variety of experiments to conventional force measurement in wind tunnel experiments, special force measurement, dynamic force measurement online self-calibration function module instrument provides programmable gain and filtering, provide a very effective means for the detection of data the DSP chip module inside the instrument, you can reduce the heavy computing work of the host computer, so that the host computer system The resources can be significantly released, to optimize system resources.

More commonly chosen VXI bus structure. Its advantages (1) highly integrated, compact structure, high reliability and strong anti-interference capability; (2) DSP (digital signal processing) chip, the function of the instrument is improved; (3) has online calibration function to simplify troubleshooting; (4) local bus makes the exchange of information between modules ability to improve, while supporting the 1394 agreement, Easy communication with the computer. (5) with an open structure and the use of flexible, easy to extend.

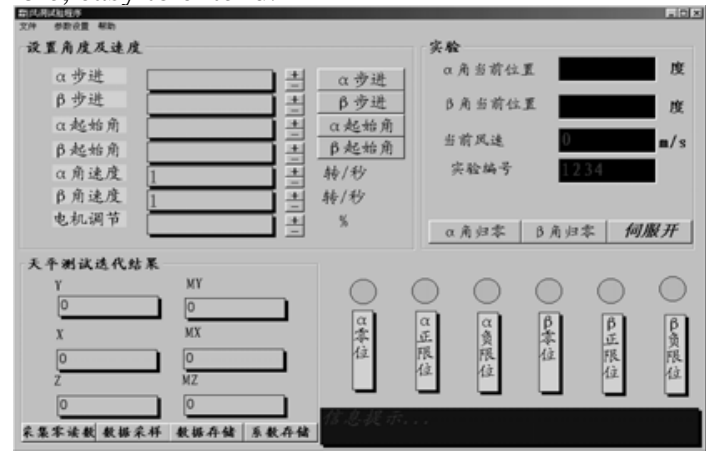

Figure 1 Data monitoring and control main panel

\section{WIND TUNNEL TEST SYSTEM DESIGN FEATURES}

$0.75 \mathrm{~m} \times 0.75 \mathrm{~m}$ backflow of low-speed wind tunnel measurement and control system has been transformed using industrial control computer as its core, reprogramming the computer control software, software programming platform based WINDOS2000 of the entire wind tunnel control system and data acquisition control and data processing systems. DC power system governor, model angle of attack, sideslip angle All-digital AC servo control, model angle, wind speed control the unification issue an enforcement instruction by the implementing agencies done automatically by the computer, the computer at the same time for data acquisition and data processing; The experimental model is given all contribute and state data curve, and the establishment of a database of model experiments, in order to Inquiry and print. After transformation, the wind tunnel measurement and control system and data acquisition system to fully automatic function.

\begin{tabular}{|c|c|c|c|c|c|c|c|}
\hline \multicolumn{8}{|c|}{ Thatided } \\
\hline \multicolumn{7}{|c|}{ 天平数据采样零读数显示 } & 数据消空 \\
\hline 时间 & a角 & B角 & $\bar{Y}$ & $\mathrm{X}$ & $z$ & MY & MX \\
\hline 9:03:29 & -4 & $\overline{0}$ & -1605.591 & -540.871 & 3312.520 & 1482.487 & 520.468 \\
\hline 9:03:56 & -3 & & -1600.093 & -517.464 & 3323.735 & 1493.336 & 551.031 \\
\hline 9:04:10 & -2 & 0 & -1604.222 & -498.434 & 3320.534 & 1489.322 & 566.649 \\
\hline 9:04:22 & -1 & 0 & -1605.701 & -479.143 & 3318.462 & 1485.982 & 560.026 \\
\hline 9:04:33 & 0 & 0 & -1606.212 & -456.737 & 3305.324 & 1477.403 & 513.245 \\
\hline 9:04:44 & 1 & & -1601.817 & -435.660 & 3317.427 & 1490.724 & 546.750 \\
\hline 9:04:54 & 2 & 0 & -1605.641 & -420.532 & 3319.482 & 1489.162 & 560.878 \\
\hline 9:05:03 & 3 & 0 & -1620.778 & -407.411 & 3287.590 & 1461.833 & 470.955 \\
\hline $9: 05: 13$ & 4 & 0 & -1606.960 & -379.767 & 3317.564 & 1491.670 & 560.268 \\
\hline $9: 05: 25$ & 5 & 0 & -1610.596 & -363.632 & 3309.192 & 1484.531 & 541.896 \\
\hline 9:05:34 & 6 & 0 & -1617.383 & -345.241 & 3292.622 & 1464.903 & 473.680 \\
\hline & & & & & & & \\
\hline
\end{tabular}

Figure 2 Collect data samples

\section{A Angle structure}

Angle structure designed for automatic control, using the Japanese all-digital AC servo angle control. Which is characterized by: (1) control, high precision, high precision angle, speed control characteristics, it has been widely used in CNC equipment and related fields. The output of the motor shaft angle accuracy of up to 5 '; (2) the output torque, constant torque output, zero speed torque output; (3) the dynamic characteristics of a good, fast from the fast stop without affecting the control accuracy; (4) small size; (5) control simple, easy maintenance.

\section{B System Control and Data Collection}

Industrial control machine to its core. DC drives, AC servo through Isolated $12 \mathrm{D} / \mathrm{A}$ card, servo multi-axis control card by the IPC to achieve automatic control according to the experimental requirements. Experimental force balance data, wind speed by the IPC by 12 high-speed A / D acquisition. The differential pressure transmitter used for the measurement of the test section of the wind speed, measured with the differential pressure transmitter relative to the static pressure of the atmosphere to calculate the wind speed of the test section. With a high input impedance, high common-mode rejection ratio, very low offset voltage and offset current, and has a wide band. Replace the motor control cabinet, and together with the corresponding low-voltage electrical (low-voltage electrical selected Schneider products), and display instrumentation. Able to show that the current wind speed, motor current, voltage, etc., the data monitoring and control panel, and samples shown in Figure 1, Figure 2.

After several tests, the data obtained are fine, reliable, and reasonable to the industry standard requirements. 


\section{ACKNOWLEDGINENT}

This paper supported by National Natural Science Foundation China (Grant NO:61172126/F010410)

\section{REFERENCES}

[1] Shihong Chang .etc Compile. wind tunnel data acquisition technology [M] .Beijing: National Defense Industry Press 2002.02

[2] Yunqilinzhu Wind tunnel experiment data error correction [M] Beijing: National Defense Industry Press, 1996.1

[3] Liu zheng-chong. tunnel structure design[M].Beijing: China Astronautic Publishing. 2005.01

[4] Wuronglin. Wind tunnel design principles [M]. Beijing : Beijing Institute of Aeronautics Press. 1985.10

[5] Shi hongchang etc. Wind tunnel data acquisition technology [M]. Beijing: National Defense Industry Press 2004.01 